\title{
How Agency-Theoretic Factors Affect the Delegation of Pricing Authority to the Sales Force: An Empirical Study
}

\author{
Alireza Fazlzadeh (Assistant Professor) \\ School of Economics, Tabriz University, Iran \\ Tel: 98-411-477-4746 E-mail: Fazlzadeh_acc@yahoo.com \\ Pegah Mohammadi (Corresponding author) \\ School of management, International Marketing management, Aras university of Tabriz, Iran \\ Tel: 98-914-348-4738Ｅ-mail: Pegah_f120@yahoo.com \\ Abolfazl sepehrfar \\ School of management, International Marketing management, Aras university of Tabriz, Iran \\ Tel: 98-913-319-5429 E-mail: a_sepehr86@yahoo.com
}

\begin{abstract}
Here we (1) empirically test a framework of important drivers of price delegation based on agency-theoretic (2) investigate the impact of price delegation on firm performance. The study data's collected from a sample of 180 companies from the industrial home appliances and structural equipment industry in Iran. Result show that, risk-aversion of salespeople is negatively and customer heterogeneity positively related to the degree of price delegation. Also we find that information asymmetry has no relationship with price delegation. Furthermore, we find a positive effect of price delegation on firm performance, which is amplified when market-related uncertainty is high and when salespeople possess better customer-related information than their managers. Hence, our results clearly show that rigid, "one price fits all" policies are inappropriate in many B2B market situations. sales managers should grant their salespeople sufficient leeway to adapt prices to changing customer requirements.
\end{abstract}

Keywords: Price delegation, Risk-aversion of salespeople, Customer heterogeneity, Information asymmetry

\section{Introduction}

Among the '4 Ps' of the marketing mix, price has a special role in that it is the only marketing instrument that alone directly generates revenues; all other marketing mix variables have costs associated with them and are subject to budget constraints. However, price has an equivocal effect on a company's bottom line as it drives a product's quantity demand as well as determines the revenue from its sales. That is, a higher price can lower demand (e.g., units sold) but, depending on the price elasticity, increase or decrease revenues and, consequently, increase or decrease profits. Thus, it is not surprising that there exists strong evidence that poor pricing can substantially deteriorate a firm's performance (e.g., Marn \& Rosiello, 1992; Nagle \& Hogan, 2006; Simon \& Butscher, 2001).

Setting optimal prices, however, is a complex problem in general and is particularly challenging in industrial or B2B market settings, where purchase prices of products and services typically vary from one customer account to another as prices are negotiated and modified from list prices in the course of the purchase process. Business marketers often rely heavily on their sales forces to inform, persuade, negotiate with, and win orders from professional purchase managers and buying teams in competitive bidding situations (e.g., Anderson, Narus, \& Narayandas, 2008; Slatter, 1987). Key issues for sales managers to understand in such competitive industrial selling situations are: (a) What are the determinants of the observed degree of pricing authority granted by different companies? (b) How is pricing authority delegation related to performance?

Proponents of delegating pricing authority to the sales force typically argue that local salespeople are in a better position to settle purchase prices than their superiors at central locations. Specifically, due to their closeness to the market, salespeople are better informed about local market conditions and customers' needs and willingness 
to pay, enabling them to determine prices at which customers will buy that are also profitable for the firm. This is in line with a rich stream of economic literature emphasizing that decision rights should be collocated with the knowledge that is valuable to those decisions (see, among others, Hayek, 1945; Jensen \& Meckling, 1992). On the other hand, there are also many firms and managers who are reluctant to decentralize pricing decisions because of the concern that salespeople will use this autonomy to make easy sales without regard to the effects on the firm's profits. This attitude is effectively summarized by Kern $(1989$, p. 44): "Letting the sales force set prices is about the same as hiring a fox to guard the hen house".

The conflicting views about price delegation are reflected by the data about its prevalence and nature from surveys of sales organizations over the years. Specifically, Stephenson, Cron, and Frazier (1979) report that only $23 \%$ of all responding firms in their survey gave full pricing authority, while $48 \%$ gave medium authority (i.e., pricing latitude was limited to pre-specified ranges), and $29 \%$ granted low pricing authority to their sales forces (i.e., sales personnel had no authority to deviate from list prices or could do so only with prior management approval). More recently, a survey by Hansen, Joseph, and Krafft (2008) found that only $11 \%$ of all firms fully delegate pricing decisions, while $28 \%$ of the responding companies yield no pricing authority at all to their sales forces (i.e., price is determined exclusively by management).

As the ambivalence about price delegation persists in sales management practice, a number of studies in the economic agency theoretic tradition aimed at explaining the observed variation in the use of price delegation as well as offering normative guidelines to sales managers have appeared (e.g., Bhardwaj, 2001; Joseph, 2001; Lal, 1986; Mishra \& Prasad, 2004, 2005). In general, this theoretical literature has converged on several key factors that should affect the degree of pricing authority delegated to sales forces. However, there are some critical differences in these papers' conclusions as to whether and when price delegation is more profitable than centralized pricing. These emanate from differences in their assumptions with regard to the process of information transmission and exchange between central sales managers and local sales representatives. Thus, this stream of theoretical research has left some ambiguity about the benefits of price delegation that needs to be resolved for its recommendations to be of more value to sales management.

To this end, research that empirically tests the extant agency theoretic insights about factors favoring more or less price delegation and predictions about the impact of delegation on the organization's performance under different conditions is sorely needed. So far, however, empirical research on price delegation is very limited in the sales management literature. Indeed, to our knowledge, the only published empirical study following the early work of Stephenson et al. (1979) is that of Hansen, Joseph, and Krafft (2008). Further, the extant empirical studies have limitations. For example, Stephenson et al. (1979) concentrate on the effects of delegating pricing authority on sales and profitability and report that those firms in their sample that gave the highest degree of pricing authority experienced the lowest sales and profit performance. However, no contingent effects were considered, and the degree of pricing authority was measured using three categories (low, limited, and full), which hardly captures subtle differences in the level of price delegation across companies. Further, their research was restricted to one specific industry. A later study by Hansen, Joseph, and Krafft (2008) investigates selected hypotheses based only on the work of Joseph (2001), thereby ignoring several common antecedents identified in other models.

Against this backdrop, the goal of our study is to improve our understanding of the focal drivers and performance effects of delegating pricing authority to sales forces. In particular, we focus on the following two research objectives: (1) Develop and test a framework of important drivers of pricing authority delegation, drawing heavily on agency-theoretic research in economics and marketing science; and (2) investigate the impact of price delegation on firm performance. We shall develop hypotheses about these different roles of key variables. We will test our research framework empirically using a newly developed multi-item scale for the focal pricing authority construct.

The rest of this paper is organized as follows: In Section 2, we present our conceptual framework and derive our hypotheses, reviewing the findings from the agency-theoretic literature. We then present important aspects of our methodology (Section 3) and key results of our empirical study (Section 4). The paper concludes with a summary of its contributions to the extant literature, implications for managers, and directions for future research (Section 5).

\section{Hypothesis development}

\subsection{Antecedents of delegation of pricing authority to the sales force}

The agency-theoretic literature suggests five key factors that bear on a firm's decision to delegate authority to sales forces: (i) information asymmetry; (ii) customer heterogeneity; (iii) environmental (sales response) 
uncertainty; (iv) sales representatives' risk aversion; and (v) difficulty in measuring sales representatives' effort inputs. In the discussion below, we first consider and develop hypotheses about the direct effects of each of these factors on price delegation, i.e., the extent of pricing authority granted by firms to their sales forces.

\subsubsection{Effect of information asymmetry}

In the sales force management context, information asymmetry exists when the salesperson has more precise information than the sales manager about the selling environment, i.e., the conditional distribution of her/his territory's or 'local' sales as a function of selling effort, price, other marketing efforts, competition, and random factors in the environment (e.g., Lal \& Staelin, 1986). The salesperson can gain this information advantage through closer proximity to customers in her/his area and by investing some part of her/his sales effort toward collecting more precise information about exactly which local conditions prevail in her/his territory. In contrast, the more remote sales manager may only know the distribution of conditions - rather than the exact conditions - prevailing in the territory. In such situations, the delegation of pricing authority provides management with the opportunity to exploit the salesperson's superior information to charge different prices for different demand conditions.

More precisely, Lal (1986) showed that as long as the compensation plan is specified to be a general function of sales and the price charged by the salesperson, price delegation is more profitable than centralized pricing when information is asymmetric. However, this result can be reversed, i.e., the firm can do equally as well, or better, with centralized pricing than with price delegation if the firm can induce the salesperson to reveal his/her private information during the process of contracting (e.g., Mishra \& Prasad, 2004, 2005). However, in reality, the design of revelation mechanisms like menus of contracts is a rather complex undertaking, and the use of such contracts is rare (e.g., Bergen, Dutta, \& Walker, 1992; Lal \& Staelin, 1986; Mantrala \& Raman, 1990; Mantrala, Sinha, \& Zoltners, 1994; Rao, 1990). In circumstances when private information held by the salesperson is not easily communicable, Mishra and Prasad (2004, p. 26) concede that Lal's result would still hold - i.e., information asymmetry would favor decentralized pricing. Accordingly, therefore, we hypothesize:

H1. Information asymmetry is related positively to the degree of pricing authority delegated to the sales force.

\subsubsection{Effect of customer heterogeneity}

In their study of pricing delegation, Stephenson et al. (1979) note that one of the market conditions under which the practice of price delegation tends to develop is when customer classes and sizes vary widely. More precisely, Lal (1986) notes that customer heterogeneity favors a higher degree of pricing authority delegation because the salesperson is more likely to possess customer-related information superior to that of central sales management when there is greater variation in sales response function characteristics across customer accounts. In this respect, customer heterogeneity can function similarly to information asymmetry. Customer heterogeneity, however, also plays an independent role in driving delegation of pricing decisions to the sales force. Specifically, in theory, greater customer heterogeneity implies there is greater value to price customization, i.e., adapting prices to customers' differing willingness to pay characteristics (Dolan \& Simon, 1996). The opportunity for price customization improves by giving salespeople who directly interact and negotiate with individual customers the authority to make such price adjustments. Following this logic, we hypothesize:

H2. Customer heterogeneity is related positively to the degree of pricing authority delegated to the sales force.

\subsubsection{Effect of market-related uncertainty}

In agency models, the uncertainty in the selling environment typically has one effect: it adds observation error to performance measures. According to Prendergast $(2000,2002)$, it also has another effect: delegation of decision making is more likely when there is greater uncertainty about what the agent should be doing. Corporate managers take control of decisions, i.e., centralize, when they are more certain about how input efforts relate to outputs as they think they can make more effective decisions. Moreover, delegating responsibilities to agents who have better access to the necessary information in highly uncertain environments makes sense because it (i) reduces the firm's costs of gathering the information required to reduce uncertainty and make better decisions (Nagar, 2002), and (ii) minimizes intra-firm information transmission inefficiencies such as leaks (Keren \& Levhari, 1989) and delays (Radner, 1993; van Zandt, 1998), which affect the quality of decisions and their ultimate implementation in the field. Based on these arguments, we hypothesize:

H3. Market-related uncertainty is related positively to the degree of pricing authority delegated to the sales force. 


\subsubsection{Effect of risk aversion}

There is empirical evidence that salespeople are more risk averse than their employers, or as Nimer (1971, p. 48) describes it: "... the salesman has the temptation always to play it safe to get the order". Thus, it is hardly surprising that agency theory models in sales force settings regularly presume risk-averse salespeople. To avoid losing contracts, a risk-averse salesperson with pricing authority would be tempted to sell on the basis of a lower price, given that her/his compensation is formally linked to immediate sales results (Jain \& Laric, 1979). From a managerial perspective, therefore, it is recommended to limit the pricing authority of salespeople who are risk averse (Dolan \& Simon, 1996). Similarly, in a formal model, Weinberg (1975) provided evidence that yielding pricing authority to riskaverse salespeople is sub-optimal. Therefore, our empirical model hypothesizes:

H4. Risk aversion of a company's sales force is related negatively to the degree of pricing authority delegated to the sales force.

\subsubsection{Effect of difficulty of input measurement}

As already noted, Prendergast $(2000,2002)$ and others have made the case that greater selling environment uncertainty would lead to more delegation. Prendergast (2002) also argues that greater delegation leads to more output-based contracts since this is the only way for central managers to assess performance. On the other hand, the case for centralized price-setting is strengthened as the ease of monitoring agents' effort inputs increases. This is because it becomes more difficult for agents to shirk and then argue that lower sales were due to a high centrally set price rather than any lack of selling effort on their part. That is, the threat of a moral hazard problem diminishes as it becomes easier to monitor the agent's input efforts. Monitoring also allows the firm to save on compensation costs by reducing incentive pay and relying more on behavior-based control systems (see, e.g., Anderson \& Oliver, 1987; Joseph \& Thevaranjan, 1998; Krafft, 1999). Thus, centralized pricing becomes more tenable and its cost relative to that of delegated pricing authority decreases as the ease of monitoring salespeople's input effort increases. Based on these insights from economic models, we hypothesize:

H5. Difficulty of measuring salespeople's input is related positively to the degree of pricing authority delegated to the sales force.

\section{Research methods}

\subsection{Data collection and sampling}

In order to test our framework and hypotheses, we conducted a survey of firms in the industrial home appliances and structural equipment industries in Iran. We selected these industries on the basis of initial interviews that indicated that companies from these B2B settings are suitable for empirical tests of our theoretical model because (a) selling processes in these industries are typically characterized by intense price negotiations and (b) companies from these industries seem to vary substantially with regard to the degree of pricing authority delegated to their salespeople. We pretested a preliminary questionnaire with a limited sample of sales managers and scholars $(\mathrm{n}=10)$, which resulted in minor modifications in wording and item selection. After conducting a second pretest in order to assess the validity of the scales, the final questionnaire was mailed to 200 companies drawn from a commercial mailing list. We obtained 185 responses, of which 180 were usable. The questionnaire was filled out by senior sales managers or executives. We view this response rate as satisfactory considering that the response rates for this level of management are usually in the range of 15 to $20 \%$ (Menon, Bharadwaj, \& Howell, 1996).

\subsection{Measure development and assessment}

With the exception of customer heterogeneity and risk aversion, all of our constructs were measured using reflective measurement models, given that each set of corresponding observed variables (and their variances and covariances) can be classified as manifestations of the underlying constructs (Bagozzi \& Baumgartner, 1994). For customer heterogeneity, a formative measure with four items was applied (Jindal, Reinartz, Krafft, \& Hoyer, 2007). A single-item measure was used for risk aversion, as described below. Most of the scale items we use are adapted from those in the existing literature, with slight modifications to match our conceptualization.

\subsubsection{Pricing authority}

We conceptualize our focal construct, 'pricing authority', as the degree to which a sales force employee is empowered to negotiate and change a product's or service's list price without consulting the sales manager. As our study is the first to measure pricing authority using a continuous and multi-item measure, we created a new scale. Based on an extensive literature review and in-depth interviews of sales managers and academics, we developed an initial list of 20 items that seemed to be related to our focal construct. A subsequent evaluation by 
sales experts indicated that only half of these items could be considered manifestations of the construct 'pricing authority'. A trial pricing authority scale with the remaining ten items was then pretested on a sample of ten sales managers, leading to the elimination of three more items. Thus, the measurement scale used in our survey consisted of seven items (see Appendix A).. Thus, our final pricing authority scale consists of seven items. The corresponding Cronbach's alpha of 847 indicates that this selection of items is adequate for our purposes.

\subsubsection{Business unit performance}

Three items adapted from Reinartz et al. (2004), who, in turn, based their selection of items on those used by Deshpandé, Farley, and Webster (1993), serve to measure business unit performance in terms of the SBU's overall performance, market share and revenue.

\subsubsection{Information asymmetry}

In the relationship between a sales force employee and her/his sales manager, two distinct types of information asymmetry can be observed.2 On the one hand, the sales manager has superior information on internal processes (e.g., cost information) and strategic issues, such as the long-term value of some accounts. On the other hand, the sales force employee is usually better informed than the sales manager about customers' preferences and sales response functions. Our conceptualization of information asymmetry refers to this latter type - the superior information about his/her customers that a salesperson has in comparison to the sales manager. This is also in line with how information asymmetry is conceptualized in agency theory models (e.g., Lal, 1986). In this vein, we measured information asymmetry via two items asking about the sales manager's knowledge regarding customers' situations and their willingness to pay relative to that possessed by the sales representatives.

\subsubsection{Customer heterogeneity}

Customer heterogeneity can result from customers' differences in several distinct characteristics and, therefore, is best operationalized in a formative rather than a reflective way (Bagozzi, 1994). Specifically, we measured customer heterogeneity with a formative four-item scale capturing diversity in customers' product and price preferences, customer valuations from the supplier's perspective, and need for salespeople's customer service-related efforts. The measurement model was partly adapted from Achrol and Stern (1988) and Jindal et al. (2007).

\subsubsection{Risk aversion}

Risk aversion was measured by a single item adapted from Cravens, Ingram, LaForge, and Young (1993) that asked respondents to indicate the average risk attitude of their salespeople on a semantic differential scale anchored from "very risk averse" (7) to "very risk seeking" (1). The pretests that were carried out showed that sales managers do not have difficulty in assessing the average risk preference of their salespeople in negotiations.

\subsubsection{Difficulty of input measurement}

Difficulty of input measurement refers to the complexity connected with the evaluation of what salespeople bring to the selling task (e.g., product knowledge), their activities to achieve distinct outcomes, and their sales strategies rather than what they measurably achieve (Anderson \& Oliver, 1987). To assess difficulty of input measurement, we used two items adapted from John and Weitz (1989) indicating both the accuracy of information used in salespeople's performance evaluations and the precision of activity reports. With these measurement items, we acknowledge that the ease or difficulty of assessing salespeople's performance with inputs is bound to the availability of accurate information on these inputs.

\subsubsection{Market-related uncertainty}

Following Homburg, Workman and Krohmer (1999), we conceptualize market-related uncertainty in terms of the degree, frequency, and unpredictability of market-related alterations. We adopt their scale for the purpose of measuring market-related uncertainty in personal selling.

\subsubsection{Reliability}

All coefficient alphas exceed Nunnally's (1978) .70 guideline. coefficient alphas are .807 (pricing authority), .777 (market-related uncertainty), .807 (business unit performance), .788 (information asymmetry), .808 (customer heterogeneity), .812 (risk aversion).

Subsequently, we conducted separate confirmatory factor analyses on each multi-item reflective construct to test for unidimensionality of measures (Gerbing \& Anderson, 1988). These analyses could only be conducted for the constructs of 'pricing authority', 'business unit performance' and 'market-related uncertainty' because the 
remaining reflective constructs contained fewer than three items and thus were not suited for this kind of analysis. The measurement model for our focal pricing delegation construct exhibited an acceptable fit, with the following overall goodness-of-fit statistics ranges: Chi-Square statistic $=5.71$; d.f. $=1$ : RMSEA=.016; RMR=.014, GFI=.99; $\mathrm{AGFI}=.75 ; \mathrm{NFI}=.99 ; \mathrm{CFI}=.99 ; \mathrm{IFI}=.99, \mathrm{RFI}=.82$ and $\mathrm{NNFI}=.85$.

\section{Results}

\subsection{Descriptive results}

Table 1 shows the means and standard deviations of all constructs as well as the correlations between constructs. The correlations indicate no signs of multicollinearity problems. Fig. 1 gives an overview of the average degrees of pricing authority in the sample (based on the average score of our five-item scale). Most companies (i.e., $76.7 \%)$ tend to delegate a average degree of pricing authority, while only small percentages delegate no (10.6\%) or complete (12.8\%) pricing authority.

\subsection{Hypothesis test results}

In order to test our hypotheses, structural equation modeling (LISREL 8.5) was applied. Model estimation results are summarized in Fig. 2. Considering that we focus on only agency-theoretic determinants of 'pricing authority'. we find strong support for our hypothesis (H2) of a positive relationship between customer heterogeneity and pricing authority $(\beta=.41, \mathrm{t}$-value $=4.01)$ This effect could occur because with greater customer heterogeneity there is greater potential for charges of price discrimination and customer antagonization if salespeople are given authority to vary the price according to their special knowledge of customers' characteristics. If central managers feel the costs of dealing with these charges or, more broadly, 'customer antagonization costs' (see, e.g., Blinder, Canetti, Lebow, \& Rudd, 1998; Rotemberg, 2005; Zbaracki, Ritson, Levy, Dutta, \& Bergen, 2004) outweigh the benefits of price customization, then they may restrict the pricing authority of salespeople as customer heterogeneity increases. and for our hypothesis ( $\mathrm{H} 4)$ of a negative impact of salespeople's risk aversion on pricing authority $(\beta=-.39, \mathrm{t}$-value=7.16). However, our hypothesis $(\mathrm{H} 1)$ of a positive relationship between information asymmetry and pricing authority is not supported $(\beta=.08$, t-value $=0.97)$. We also do not find support for our hypothesis $(\mathrm{H} 3)$ of a positive relationship between the extent of market-related uncertainty and the delegation of pricing authority and hypothesis (H5) of a positive relationship between difficulty of input measurement and delegation of pricing authority $(\beta=.09$, $\mathrm{t}$-value $=1.39)$. Again, this could be because the customer costs of pricing adjustments can be substantial and increase with their frequency (e.g., Zbaracki et al., 2004). Further, the frequency of adjustments is likely to be higher in more volatile sales environments. If managers feel that the higher costs of pricing adjustments outweigh the benefits of price customization, they may not expand sales force pricing authority as market-related uncertainty increases. Turning to the impact of pricing authority on business unit performance, we find a positive and significant direct relationship $(\beta=.96$, $\mathrm{t}$-value $=7.55$ ), as hypothesized (H6).

\section{Discussion}

\subsection{Summary of contributions}

This study is the first to provide a comprehensive empirical test of agency-theoretic drivers of price delegation, combining the congruence and consonance perspectives within contingency theory (Mahajan \& Churchill, 1990). Following the congruence approach, we found that information asymmetry, salesperson risk aversion, and difficulty of selling input measurement significantly impact delegation of pricing authority.

Our general finding that pricing authority is associated with higher levels of business unit performance (as proposed in H6) is significant from two viewpoints. First, this result confirms theoretical arguments that can be found in the economic and agency-theoretic literature (e.g., Jensen \& Meckling, 1992; Lal, 1986Weinberg, 1975, 1978;), emphasizing that decision rights should be co-located with the knowledge that is valuable to those decisions.

One reason why our findings differ from those of Stephenson et al. (1979) could be the significant time gap of almost 30 years since the Stephenson et al. study. Since the late 1970s, companies have substantially improved their information systems. Most sales forces are now equipped with sales automation technology that enables salespeople to make more qualified autonomous decisions (Ahearne, Hughes, \& Schillewaert, 2007; Ahearne, Jones, Rapp, \& Mathieu, 2008). There has also been an increase in customized marketing and sales activities, including individualized pricing, that call for salespeople to have more pricing flexibility. Another possible reason why our findings are different from those of Stephenson et al. (1979) is that the present study is based on a broad range of manufacturing companies from two industries: home appliances and structural equipment. In contrast, Stephenson et al.'s (1979) study focuses on one very specific industry, namely wholesale firms that 
distribute medical supplies and equipment. It is likely that buyer-seller negotiations in the industries we have surveyed are more complex and wide-ranging, focusing on the customer's trade-offs between price and value of the offering, than they are at a wholesaler level, where the focus may simply be on settling price discounts. That is, there may be greater opportunity for the theoretical benefits of pricing authority delegation to be realized by firms in our sample than by the firms in Stephenson et al.'s (1979) study.

\subsection{Implications for managers}

Probably the most interesting implications that managers can derive from our study pertain to the direct and moderated performance impacts of the pricing delegation decision. Overall, our study results offer strong empirical support for the notion that rigid, one-price policies are inappropriate in many B2B market situations. As a consequence, sales managers should grant their salespeople sufficient leeway to adapt prices to changing customer requirements and market conditions. This is especially true if firms operate in highly turbulent and uncertain selling environments. This finding is important for managers since it empirically confirms recommendations offered in the economics and agency-theoretic literature that managers should capitalize on the superior market and customer knowledge of their field salespeople by giving them sufficient leeway to negotiate prices autonomously. Lastly, our empirical findings offer another interesting insight: concerning the performance effects of pricing authority, it becomes clear that what the vast majority of companies do (i.e., delegate substantial pricing authority to their salespeople, see Fig. 1) is, on average, the most successful strategy. When it comes to pricing delegation decisions, it therefore seems more advisable to conform with rather than deviate from prevailing industry practices. This general result is similar to previous findings in empirical sales force studies (e.g., Anderson, 1988), suggesting that descriptive findings have normative implications, i.e., predominant industry practices may serve as a reasonable benchmark.

While the development of a full-blown normative model is beyond the scope of this research, the findings of our theory-driven empirical study and past theoretical research offer some guidelines for how a firm considering whether and how much to delegate pricing authority to its sales representatives should proceed.

First, the firm should determine if the necessary preconditions for any pricing authority delegation exist. As a first step, the firm should assess the degree of information asymmetry that prevails between sales representatives and management. The key question here is whether the firm's knowledge about its customers (e.g., the price each is willing to pay) is comparable to its salespeople's. If the answer to this question is 'Yes', then no pricing authority needs be delegated. However, if the answer is 'No', then the firm should assess its salespeople's motivation to respond to price delegation in the manner desired by the firm as reflected by their degree of risk aversion. According to our findings and extant theory, price delegation is worthwhile to consider only if the latter is "moderate to low". If this is indeed the case, the firm should carefully assess the extent of its information needs relative to the knowledge possessed by its representatives. Full pricing delegation (subject, perhaps, to some general upper or lower bounds on prices) would be warranted if management is ignorant about not just each individual customer's type, but also about the distribution of customer types in the market. On the other hand, limited pricing delegation may be sufficient if the firm knows the distribution of customer types but does not know each customer's exact type. In such a situation, the firm can specify the price that each type of customer must be charged but leave it to the salesperson to identify each customer's specific type (and, hence, to select the price for that customer). Next, the firm should assess the expected costs of the salesperson compensation plan accompanying price delegation. Following Weinberg $(1975,1978)$ and Lal $(1986)$, for price delegation to work, the compensation plan itself should tie a portion of the agent's incentive pay to the profitability (gross margins) of his/her sales. In the case of limited price delegation, the incentive plan could take the form of a menu of compensation contracts wherein each contract is tied to the price set by the salesperson to avoid adverse selection problems (e.g., Lal \& Staelin, 1986).

If the expected costs of designing and implementing a suitable compensation plan exceed the benefits of price delegation, the firm should avoid delegating any pricing authority. However, even if price delegation appears more profitable than centralized pricing at this stage, the firm should still assess as a last step whether it would be more economical to overcome its fundamental information asymmetry problem in some other way. For example, the firm can invest in increased monitoring and information gathering by its front line managers and develop an appropriate non-linear pricing plan for its heterogeneous customers that its salespeople should present to all of their customers without further price negotiations. It is only if such direct investments and actions by the firm are less profitable that the firm should proceed with delegation of pricing authority to its sales force. 


\subsection{Directions for further research}

The scope of the present study was limited to tests of major contingency factors derived from agency theory. Thus, our research framework does not encompass all possible variables and facets that might be relevant to the pricing authority delegation decision. However, one of our model validation checks indicated that integration of the two control variables "centralization" and "use of sales force automation" strongly increases model fit, which implies that the decision to delegate pricing authority is also influenced by structural variables and the use of information technologies. Similarly, salesperson characteristics related to their knowledge and competence levels might also influence the pricing authority decision. Investigating the impact of such additional variables is a worthwhile direction for future research. The empirical testing of our proposed framework has relied on perceptual measures of constructs provided by the sales executives surveyed. This is a reasonable approach for our study considering that sales executives' price delegation decisions are driven by their own perceptions rather than by the "objective" values of the various contingency factors (see, e.g., Krafft, Albers, \& Lal, 2004). However, future studies that integrate perceptual and objective measures of constructs such as risk aversion and information asymmetry in their analyses may lead to more robust tests of economic explanations of observed variations in pricing authority delegation and its effects on performance.

Another promising extension of our research would be to investigate in greater detail the intermediate mechanisms through which the delegation of pricing authority influences final performance outcomes at the firm level. While the present study provides consistent empirical support for the hypothesis that overall firm performance can be enhanced by price delegation, the motivational and behavioral processes at the performance deserves further research.

Intermediate outcomes that are likely to be influenced by pricing authority and, in turn, influence firm performance are the pursuit of specific selling approaches (e.g., hard selling, adaptive selling, relationship selling, and value-based selling), the motivation to work hard to achieve sales targets (versus pursuing the "path of least resistance", i.e., substitute effort for discounting), intrinsic work motivation, and job satisfaction. At this stage, these intermediate processes through which pricing delegation decisions may influence firm performance still remain somewhat speculative. To conclude, we believe that our study represents a substantial contribution to the pricing delegation literature. Empirical research in the pricing delegation arena has been almost non-existent, and, to the best of our knowledge, this study is the first that comprehensively investigates both antecedents and consequences of the pricing delegation decision. More specifically, this study contributes to the literature by (1) confirming empirically the negative impact of risk aversion, the positive effects of information asymmetry and the difficulty of input measurement on the degree of pricing authority and by (2) examining the direct and moderated performance impact of pricing delegation decisions.

\section{References}

Achrol, R. S., \& Stern, L. W. (1988). Environmental determinants of decision-making uncertainty in marketing channels. Journal of Marketing Research, 25(1), 36-50.

Ahearne, M., Hughes, D. E., \& Schillewaert, N. (2007). Why sales reps should welcome information technology: Measuring the impact of CRM-based IT on sales effectiveness. International Journal of Research in Marketing, 24, 336-349.

Ahearne, M., Jones, E., Rapp, A., \& Mathieu, J. (2008). High touch through high tech: The impact of salesperson technology usage on sales performance via mediating mechanisms. Management Science, 54(4), 671-685.

Anderson, E. (1988). Strategic implications of Darwinian economics for selling efficiency and choice of integrated or independent sales forces. Management Science, 34(5), 599-618.

Anderson, J. C., Narus, J. A., \& Narayandas, D. (2008). Business market management: Understanding, creating, and delivering value, 3rd ed. Upper Saddle River (NJ): Prentice Hall.

Anderson, E., \& Oliver, R. L. (1987). Perspectives on behavior-based versus outcome based sales force control systems. Journal of Marketing, 51(4), 76-88.

Bagozzi, R. P. (1994). Structural equation models in marketing research: Basic principles. In R. P. Bagozzi (Ed.), Principles of marketing research (pp. 317-385). Cambridge, UK: Blackwell Publishers.

Bagozzi, R. P., \& Baumgartner, H. (1994). The evaluation of structural equation models and hypothesis testing. In R. P. Bagozzi (Ed.), Principles of marketing research (pp. 386-422). Cambridge, UK: Blackwell Publishers. 
Bagozzi, R. P., \& Yi, Y. (1988). On the evaluation of structural equation models. Journal of the Academy of Marketing Science, 16(1), 74-94.

Bergen, M., Dutta, S., \& Walker, O. C. (1992). Agency relationships in marketing: A review of the implications and applications of agency and related theories. Journal of Marketing, 56(3), 1-24.

Bhardwaj, P. (2001). Delegating pricing decisions. Marketing Science, 20(2), 143-169.

Blinder, A. S., Canetti, E. R. D., Lebow, D. E., \& Rudd, J. B. (1998). Asking about prices: A new approach to understanding price stickiness. New York: Russell Sage Foundation.

Chin, W. W., Marcolin, B. L., \& Newsted, P. R. (2003). A partial least squares latent variable modeling approach for measuring interaction effects: Results from a Monte Carlo simulation study and an electronic-mail emotion/adoption study. Information Systems Research, 14(2), 189-217.

Cortina, J. M. (1993). What is coefficient alpha? An examination of theory and applications. Journal of Applied Psychology, 78(1), 98-104.

Cravens, D. W., Ingram, T. N., LaForge, R. W., \& Young, C. E. (1993). Behavior-based and outcome-based salesforce control systems. Journal of Marketing, 57(4), 47-59.

Deshpandé, R., Farley, J. U., \& Webster, F. E. (1993). Corporate culture, customer orientation, and innovativeness in Japanese firms: A quadrad analysis. Journal of Marketing, 57(1), $23-37$.

Dolan, R. J., \& Simon, H. (1996). Power pricing: How managing price transforms the bottom line. New York: The Free Press.

Drazin, R., \& Van de Ven, A. H. (1985). Alternative forms of fit in contingency theory. Administrative Science Quarterly, 30, 514-539.

Dunn, S. C., Seaker, R. F., \&Waller, M. A. (1994). Latent variables in business logistics research: Scale development and validation. Journal of Business Logistics, 15(2), 145-172.

Fornell, C., \& Larcker, D. F. (1981). Evaluating structural equation models with unobservable variables and measurement errors. Journal of Marketing Research, 18(3), 39-50.

Gerbing, D. W., \& Anderson, J. C. (1988). An updated paradigm for scale development incorporating unidimensionality and its assessment. Journal of Marketing Research, 25(2), 186-192.

Han, J. K., Kim, N., \& Srivastava, R. K. (1998). Market orientation and organizational performance: Is innovation a missing link? Journal of Marketing, 62(4), 30-45.

Hansen, A., Joseph, K., \& Krafft, M. (2008). Price-delegation in sales organizations. Business Research, 1(1), 94-104.

Hausman, J. A. (1978). Specification tests in econometrics. Econometrica, 46, 1251-1271.

Hayek, F. A. (1945). The use of knowledge in society. American Economic Review, 35(4), 519-530.

Homburg, Ch., Workman Jr., J. P., \& Krohmer, H. (1999). Marketing's influence within the firm. Journal of Marketing, 63(2), 1-17.

Jain, S. S., \& Laric, M. V. (1979). A framework for strategic industrial pricing. Industrial Marketing Management, 8, 75-80.

Jayachandran, S., Sharma, S., Kaufman, P., \& Raman, P. (2005). The role of relational information processes and technology use in customer relationship management. Journal of Marketing, 69(4), 177-192.

Jensen, M., \& Meckling, W. (1992). Specific and general knowledge and organizational structure. Journal of Applied Corporate Finance, 8(2), 4-18.

Jindal, R. P., Reinartz, W., Krafft, M., \& Hoyer, W. D. (2007). Determinants of the variety of routes to market. International Journal of Research in Marketing, 24(1), 17-29.

John, G., \& Weitz, B. A. (1989). Salesforce compensation: An empirical investigation of factors related to use of salary versus incentive compensation. Journal of Marketing Research, 26(1), 1-14.

Joseph, K. (2001). On the optimality of delegating pricing authority to the sales force. Journal of Marketing, 65(1), 62-70.

Joseph, K., \& Thevaranjan, A. (1998). Monitoring and incentives in sales organizations: An agency-theoretic perspective. Marketing Science, 17(2), 107-123. 
Keren, M., \& Levhari, D. (1989). Decentralization, aggregation, control loss and costs in a hierarchical model of the firm. Journal of Economic Behavior and Organization, 11, 213-236.

Kern, R. (1989). Letting your salespeople set prices. Sales and Marketing Management, 14, 44-49.

Krafft, M. (1999). An empirical investigation of the antecedents of sales force control systems. Journal of Marketing, 63(3), 120-134.

Krafft, M., Albers, S., \& Lal, R. (2004). Relative explanatory power of agency theory and transaction cost analysis in German salesforces. International Journal of Research in Marketing, 21, 265-283.

Lal, R. (1986). Delegating pricing responsibility to the salesforce. Marketing Science, 5(2), 159-168.

Lal, R., \& Staelin, R. (1986). Sales force compensation plans in environments with asymmetric information. Marketing Science, 5(3), 179-198.

Mahajan, J., \& Churchill Jr., G. A. (1990). Alternative approaches for investigating contingency-based organizational predictions in personal selling. International Journal of Research in Marketing, 7, 149-169.

Mantrala, M. K., \& Raman, K. (1990). Analysis of a sales force incentive plan for accurate sales forecasting and performance. International Journal of Research in Marketing, 7(2/3), 189-202.

Mantrala, M. K., Sinha, P., \& Zoltners, A. A. (1994). Structuring a multiproduct sales quota-bonus plan for a heterogeneous sales force: A practical model-based approach. Marketing Science, 13(2), 121-144.

Marn, M. V., \& Rosiello, R. L. (1992). Managing price, gaining profit. Harvard Business Review, 70(5), 84-94.

Menon, A., Bharadwaj, S. G., Adidam, P. T., \& Edison, S. W. (1999). Antecedents and consequences of marketing strategy making - A model and a test. Journal of Marketing, 63(2), 18-40.

Menon, A., Bharadwaj, S. G., \& Howell, R. (1996). The quality and effectiveness of marketing strategy: Effects of functional and dysfunctional conflict in intraorganizational relationships. Journal of the Academy of Marketing Science, 24(4), 299-313.

Mishra, B. K., \& Prasad, A. (2005). Delegating pricing decisions in competitive markets with symmetric and asymmetric information. Marketing Science, 24(3), 490-497.

Mishra, B. K., \& Prasad, A. (2004). Centralized pricing versus delegating pricing to the sales force under information asymmetry. Marketing Science, 23(1), 21-28.

Moorman, C., \& Miner, A. S. (1998). The convergence of planning and execution: Improvisation in new product development. Journal of Marketing, 62(3), 1-20.

Nagar, V. (2002). Delegation and incentive compensation. The Accounting Review, 22(2), 379-395.

Nagle, T. T., \& Hogan, J. E. (2006). The strategy and tactics of pricing: A guide to growing more profitability, 4th ed. Upper Saddle River (NJ): Prentice Hall.

Nimer, D. (1971). Nimer on pricing. Industrial Marketing Management, 1, 48-51.

Nunnally, J. C. (1978). Psychometric theory. New York: McGraw-Hill.

Pennings, J. M. (1975). The relevance of the structural contingency model for organizational effectiveness. Administrative Science Quarterly, 30, 391-410.

Podsakoff, P. M., \& Organ, D. W. (1986). Self-reports in organizational research: Problems and prospects. Journal of Management, 12(4), 531-544.

Prendergast, C. (2000). What trade-off of risk and incentives? American. Economic Review Papers and Proceedings, 90, 421-425.

Prendergast, C. (2002). The tenuous trade-off between risk and incentives. Journal of Political Economy, 110(5), 1071-1102.

Radner, R. (1993). The organization in decentralized information processing. Econometrica, 61, 1109-1146.

Rao, R. C. (1990). Compensating heterogeneous salesforces: Some explicit solutions. Marketing Science, 10, 319-341.

Rapp, A., Ahearne, M., Mathieu, J., \& Schillewaert, N. (2006). The impact of knowledge and empowerment on working smart and working hard: The moderating role of experience. International Journal of Research in Marketing, 23, 279-293. 
Rotemberg, J. J. (2005). Customer anger at price increases, changes in the frequency of price adjustment and monetary policy. Journal of Monetary Economics, 52(5), 829-852.

Simon, H., \& Butscher, S. A. (2001). Individualised pricing: Boosting profitability with the higher art of power pricing. European Management Journal, 19(2), 109-114.

Slatter, S. S. (1987). The salesman's job in competitive bidding situations. Industrial Marketing Management, 16, 201-205.

Stephenson, P. R., Cron, W. L., \& Frazier, G. L. (1979). Delegating pricing authority to the sales force: The effects on sales and profit performance. Journal of Marketing, 43(2), 21-28.

Van Zandt, T. (1998). Organizations with an endogenous number of information processing agents. In M. Majumdar (Ed.), Organizations with Incomplete Information (pp. 239-305). Cambridge, UK: Cambridge University Press.

Weinberg, C. B. (1975). An optimal commission plan for salesmen's control over price. Management Science, 21, 937-943.

Weinberg, C. B. (1978). Jointly optimal sales commissions for nonincome maximizing sales forces. Management Science, 24, 1252-1258.

Zbaracki, M. J., Ritson, M., Levy, D., Dutta, S., \& Bergen, M. (2004). Managerial and customer costs of price adjustment: Direct evidence from industrial markets. Review of Economics and Statistics, 86(2), 514-533.

Table 1. Descriptive statistics

\begin{tabular}{|l|c|c|c|c|c|c|c|c|c|c|c|}
\hline \multicolumn{1}{|c|}{ variables } & MEAN & S.D & MIN & MAX & 1 & 2 & 3 & 4 & 5 & 6 & 7 \\
\hline 1. Pricing authority & 2.79 & 1.13 & 1 & 5 & - & & & & & & \\
\hline 2. Business unit performance & 2.43 & 1.01 & 1 & 4.50 & 0.70 & - & & & & & \\
\hline 3. Information asymmetry & 3.18 & 0.86 & 1.50 & 4.50 & 0.42 & 0.42 & - & & & & \\
\hline 4. Customer heterogeneity & 3.08 & 0.88 & 1 & 5 & 0.64 & 0.3 .9 & 0.64 & - & & & \\
\hline 5. Risk aversion & 2.62 & 1.23 & 1 & 5 & 0.66 & 0.55 & 0.24 & 0.45 & - & & \\
\hline 6. Difficulty of input measurement & 3.41 & 1.09 & 1 & 5 & 0.60 & 0.36 & 0.40 & 0.62 & 0.52 & - & \\
\hline 7. Market-related uncertainty & 3.54 & 0.81 & 1.50 & 5 & 0.55 & 0.35 & 0.42 & 0.59 & 0.53 & 0.55 & - \\
\hline
\end{tabular}




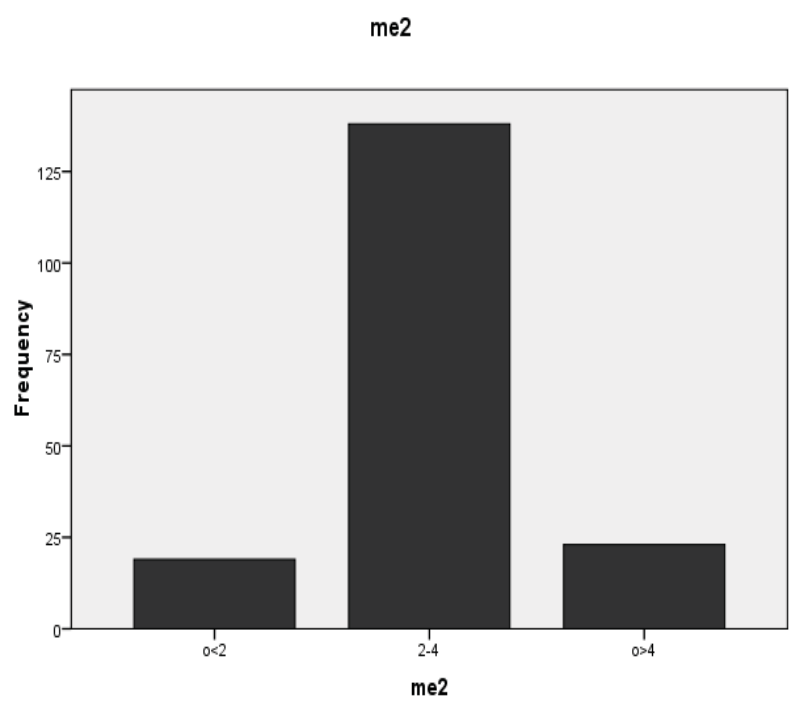

Figure 1. Average delegation of pricing authority $(n=180)$

$\mathrm{O}<2$ : low pricing authority $(10.6 \%)$

2-4: average pricing authority $(76.7 \%)$

$\mathrm{O}>4$ : high pricing authority (12.8\%)

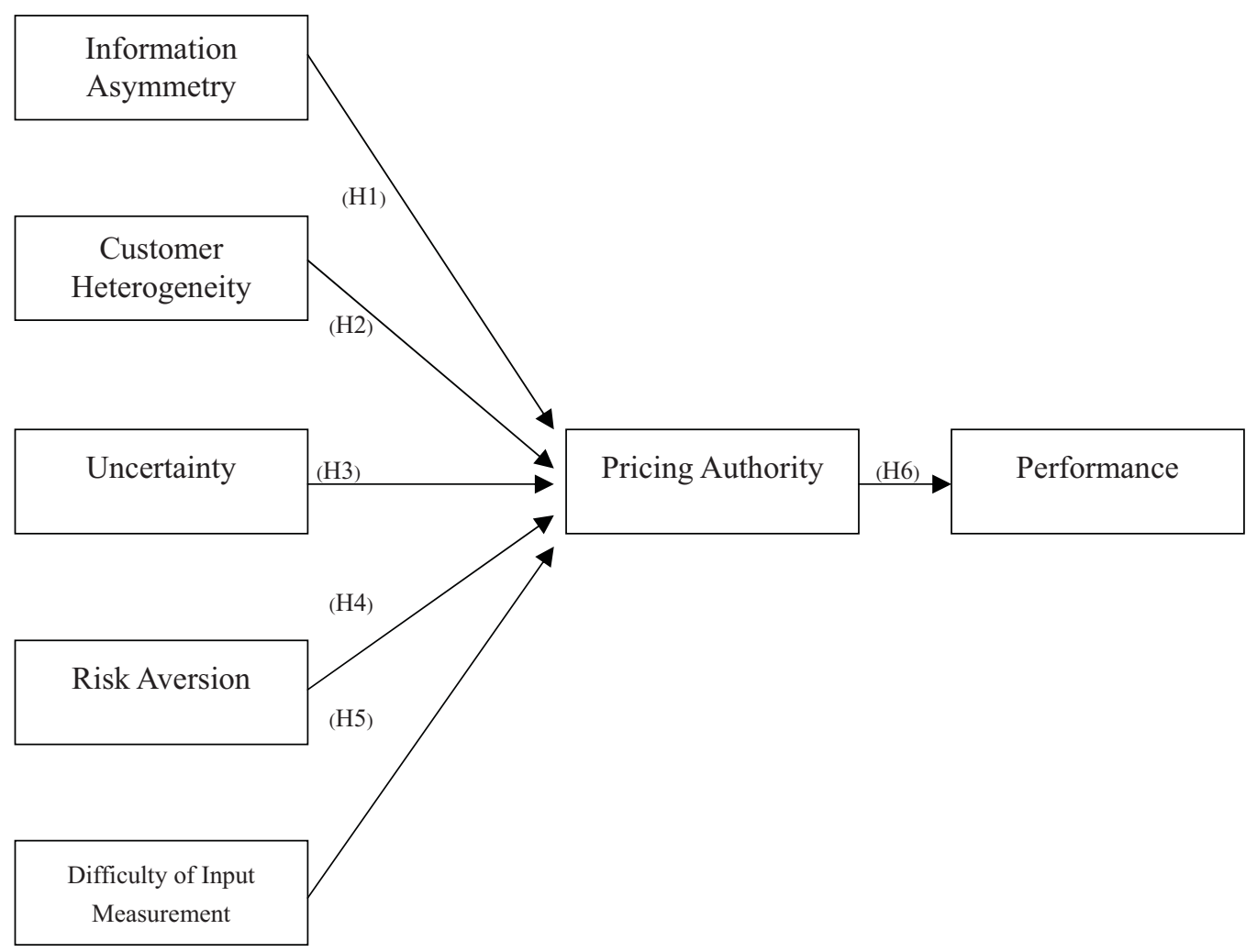

Figure 2. Path analysis 